\title{
Ocular psoriasis
}

\section{PETER EUSTACE AND DERMOT PIERSE}

Croydon Eye Unit

Although psoriasis is said to occur in 2 per cent. of the general population (Ingram, I964), ocular involvement is a comparative rarity. The lids, conjunctiva, and cornea may be involved and anterior uveitis has been described in association with the arthropathic form of psoriasis (Wright, 1959). This paper presents two patients with ocular psoriasis.

\section{Case reports}

Case 1. A r5-year-old girl presented at the Croydon Eye Unit on March 15. 1966, with a left inferior marginal keratitis which healed after topical applications of chloramphenicol ointment to leave a vascularized scar, and 2 years later she attended again with a recurrence of corneal ulceration at the same site. This time the ulcer took longer to heal. She came back 4 months later with a mild follicular conjunctivitis, and this recurred in April, 1969 .

A further episode of discomfort brought her back to the Unit on February 16, 1970, and at this time it was noted that there were unusual and distinctive features in the corneal lesion: namely a fairly superficial tongue of opacity extending inwards about $3 \mathrm{~mm}$. infero-temporally in the left ey\& $\vec{\oplus}$ with slight guttering and several discrete whitish slightly irregular dots (Fig. I). It was thought. possible that the mild psoriasis, from which she had suffered since childhood, was connected with these lesions. Direct questioning revealed the fact that on two occasions the episodes of ocular inflammation coincided with cutaneous relapses. The diagnosis of psoriasis was confirmed by a dermatologist.

Case 2. A 42-year old-man attended the Casualty Department of the Groydon Eye Unit on February 13, 1970, with a severe right marginal keratoconjunctivitis which settled over a period of 4 weeks after intensive topical administration of corticosteroids. Marginal infiltration of the left cornea of an unusual nature was noted (Fig. 2). The patient admitted to recurrent inflammatory ocular episodes occurring about twice yearly in either eye for the previous to years. Scalp lesions suggestive of psoriasis were noted and this diagnosis was confirmed by a dermatologist.

\section{Discussion}

Psoriasis is one of the common dry scaly dermatoses. Rare in childhood and with about $\frac{9}{3}$ an equal sex incidence, it is subdivided into various clinical groupings dependent on $\frac{D}{D}$ anatomical site, and the extent and persistence of lesions. Typically, the primary lesion consists of a small flat round or oval sharply-demarcated papule covered with a delicate $\sigma$ silvery scale, distribution being roughly symmetrical with a predilection for the extensor $N$ surfaces of the extremities.

Psoriasis may involve the lids, conjunctiva, cornea, and anterior uveal tract. Plaques may appear on the lid and lid margins, though often the appearance is simply that of a red swollen lid. A nonspecific conjunctivitis usually with considerable secretion occurs, and healing may produce trichiasis, symblepharon, and a "dry eye" (Kaldeck, 1953). Demarcated yellowish red plaques have been seen on the palpebral conjunctiva (Rossler, 


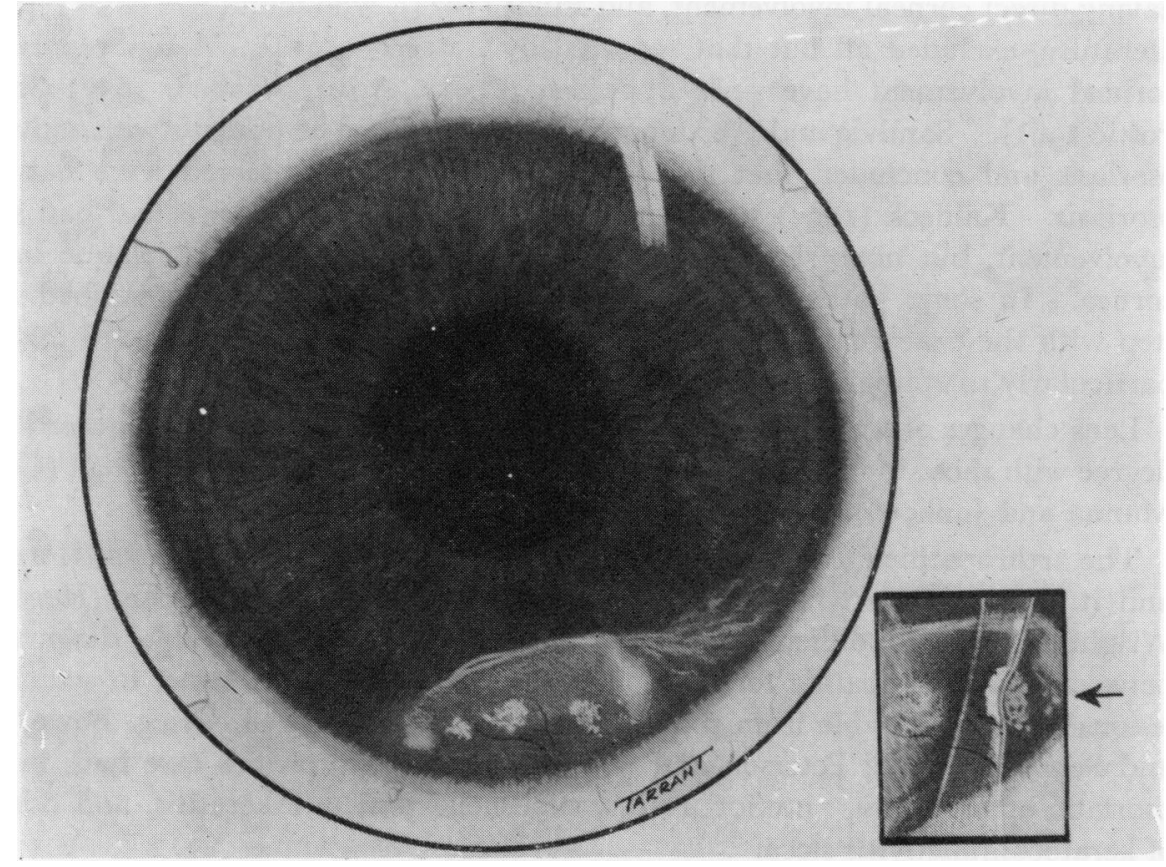

FIG I. Drawing of left cornea with slit-lamp optical section inset

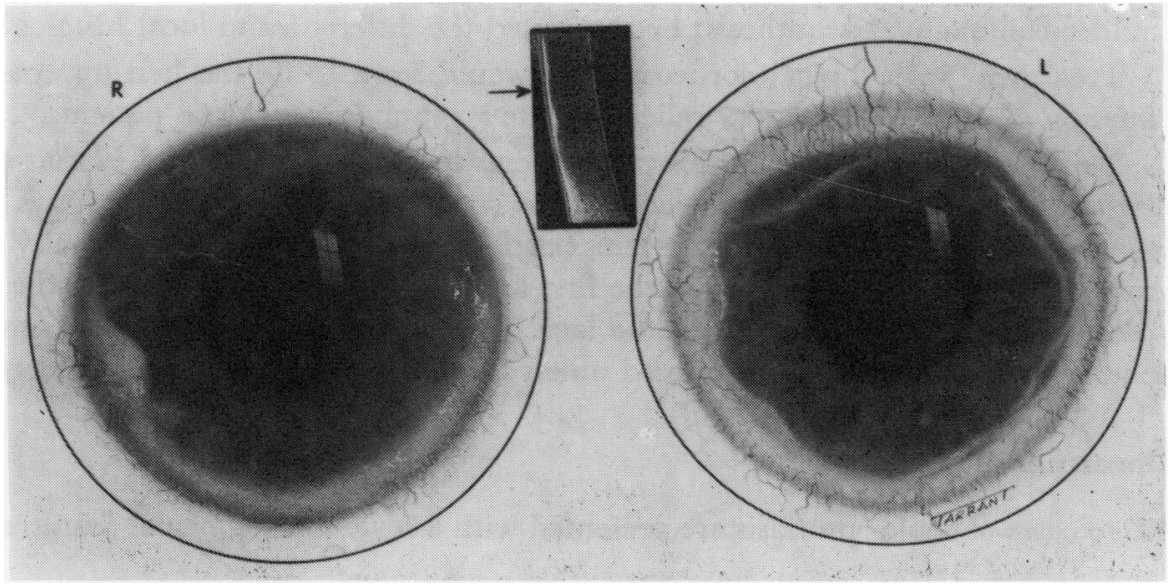

FIG 2. Drawings of both corneae with slit-lamp optical section inset.

1947), and nodular excrescences of piled-up epithelium at the limbus with surrounding stromal opacity were described by Stuart ( 1963 ). These lesions resembled those sometimes seen in rosacea (Starr and MacDonald, 1969). The cornea may be involved in a nonspecific fashion, the commonest presentation being superficial punctate keratitis; a marginal keratitis occurs less frequently (Fontana, 1953). The distinctive picture specific to psoriatic involvement of the cornea was considered by Pillat (1934) to show three elements: a thickening of the epithelium with multiple erosions; an infiltrated zone beneath Bowman's membrane with superficial vascularization; and homogenous deep opacities. This description excludes several reported cases of ocular psoriasis from being considered as 
MAXWell, J. D., GReig, W. R., Boyle, J. A., PASieczny, T., and SGhofield, G. B. S. (1966) Scot. med. F., 11,14

OXILIA, E. (1949) G. ital. Oftal., 2, 122

PETERson, c. C., and silbiger, M. L. (1967) Amer. F. Roentgenol., ror, 86o

PILlAt, A. (1934) Klin. Mbl. Augenheilk.; 93, 75I

poštić, D. (196I) Med. Pregl., 14, 25

RÖssLer, F. (1947) Wien. klin. Wschr., 59, 819

SANDVIG, K., and WESTERBERG, P. (1955) Acta ophthal. (Kbh.), 33, 465

StARR, P. A. J., and MAcDonald, A. (ig69) Proc. roy. Soc. Med., 62, 9

StUART, J. A. (1963) Amer. F. Ophthal., 55, 6I5

VRABEC, F. (1952) Ophthalmologica (Basel), 124, 105

WRight, v. (1959) Amer. F. Med., 27, 454 